\title{
COMPARISON OF TEICOPLANIN DISK DIFFUSION AND BROTH MICRODILUTION METHODS AGAINST CLINICAL ISOLATES OF STAPHYLOCOCCUS AUREUS AND S. EPIDERMIDIS
}

\section{Carlos Henrique Camargo'; Alessandro Lia Mondelli²; Paulo José Fortes Villas Bôas²}

\begin{abstract}
${ }^{1}$ Universidade Estadual Paulista, Instituto de Biociências de Botucatu, Departamento de Microbiologia e Imunologia, Botucatu, SP, Brasil; ${ }^{2}$ Universidade Estadual Paulista, Faculdade de Medicina de Botucatu, Departamento de Clínica Médica, Botucatu, SP, Brasil.
\end{abstract}

Submitted: June 16, 2010; Returned to authors for corrections: January 03, 2011; Approved: May 23, 2011.

\begin{abstract}
The CLSI M100-S19 document has recommended the disuse of vancomycin disks for staphylococci and informed that studies on the action of teicoplanin in disk-diffusion testing should be performed. We describe the comparison of two methods, disk diffusion and broth microdilution, for determining teicoplanin susceptibility in clinical isolates of staphylococci. Overall results showed an aggregation rate of 96.8\%; Staphylococcus aureus showed total agreement while S. epidermidis showed 93.8\% of agreement. According to these local results, disk diffusion can still be employed to teicoplanin susceptibility determination for staphylococci in our institution.
\end{abstract}

Key words: Teicoplanin; susceptibility tests; S. aureus; S. epidermidis.

The class of glycopeptide antibiotics has two major representatives: teicoplanin and vancomycin. These antimicrobial agents are employed against beta lactam-resistant isolates, especially methicillin-resistant Staphylococcus aureus (MRSA) (8). Vancomycin is widely used in the United States $(8,9)$ while teicoplanin is utilized at same rates as those of vancomycin in Europe (12). The determination of susceptibility to glycopeptides became very important after the description of resistant enterococci (3) and staphylococci to such antimicrobials $(1,2,13)$. The Clinical and Laboratory Standards Institute (CLSI) annually updates the breakpoints recommended for susceptibility determination by disk diffusion and for minimal inhibitory concentration (MIC) for different antimicrobial agents and microorganisms. The M100-S19 (5) protocol removed the vancomycin disk breakpoint for staphylococci as well as described a recommendation concerning teicoplanin disk breakpoints (Note 21, p. 57): "Teicoplanin disk diffusion breakpoints were not reevaluated concurrently with the reevaluation of vancomycin disk diffusion breakpoints during recent studies. Therefore, the ability of these teicoplanin breakpoints to differentiate teicoplanin-intermediate and teicoplanin-resistant staphylococci from teicoplanin-susceptible strains is not known". The new M100-S20 (6) has also maintained this information. Differently, the European Committee on Antimicrobial Susceptibility Testing (EUCAST) reports that 
the disk-diffusion method is unreliable for both vancomycin and teicoplanin testing (EUCAST breakpoint tables $\mathrm{v} 1.1$ (April 27, 2010), available at http://www.eucast.org/eucast_ disk_diffusion_test/breakpoints/). Considering the need for new information on the possibility of using the disk-diffusion method to determine teicoplanin susceptibility, we compared such method with the gold standard reference test, the minimal inhibitory concentration determination, by using the broth microdilution method against clinical isolates of $S$. aureus and S. epidermidis.

Sixty-three samples isolated from bloodstream infections and two standard samples (S. aureus ATCC 25923, S. aureus ATCC 29213) were evaluated. The staphylococci were isolated from bloodstream infections from patients attended at the University Hospital of Botucatu Medical School, São Paulo state, Brazil, a regional reference tertiary hospital, from January to July 2009 (Table 1). Isolates were identified by Gram staining, catalase and coagulase tests, and coagulasenegative staphylococci were submitted to the simplified identification scheme proposed by Cunha et al. (7). Susceptibility tests were carried out as described by CLSI (4, 5): the disk-diffusion method using inoculums of 0.5 according to the MacFarland standard scale, on Mueller-Hinton Agar plates (Oxoid) and a $30 \mu \mathrm{g}$ teicoplanin disk (Oxoid). The broth microdilution test was carried out by using serial concentrations of teicoplanin (Sanofi-Pasteur), in cationadjusted Mueller-Hinton broth (Difco BD), ranging from 0.016 to $512 \mu \mathrm{g} / \mathrm{mL}$, on a microtitulation plate. After incubation for 18-24 hours, the inhibition zone diameter and the minimal inhibitory concentrations were evaluated. The cutoff values for both tests followed the CLSI document M100-S19 (5). Agreement between the methods was defined as the same category of susceptibility. Errors were defined as: very major error, resulting from false susceptibility by the disk-diffusion test; major error, resulting from false resistance produced by the disk-diffusion test; and minor error, intermediate result by the disk-diffusion method and a resistant or susceptible category by the microdilution test. Unacceptable error levels were $\geq 1.5 \%$ for very major errors, $\geq 3 \%$ for major errors and $10 \%$ for minor errors as recommended in the CLSI (formerly NCCLS) document M23-A2 (11).

The reference ATCC strains showed results as expected by the CLSI guideline (5), both for disk-diffusion and brothmicrodilution tests.

From the 63 staphylococci (methicillin-resistant and sensible samples), 31 were $S$. aureus, and 32 were $S$. epidermidis. The minimal inhibitory concentration (MIC) that inhibited 50 and $90 \%$ of the isolates were 1.0 and $4.0 \mu \mathrm{g} / \mathrm{ml}$, respectively. All staphylococci samples showed susceptibility $(95.2 \%)$ or intermediate resistance $(4.8 \%)$ to teicoplanin, according to the gold-standard method - broth microdilution. The three samples with intermediate resistance to teicoplanin were $S$. epidermidis.

The overall agreement between disk-diffusion and reference broth-microdilution tests was of $96.8 \%$. All the discordant staphylococci samples (2 isolates; $3.2 \%$ ) were identified as $S$. epidermidis and showed minor errors, thus ensuring approval of the disk diffusion test for teicoplanin (Figure 1).

The observed results can be viewed as an attempt to preserve disk diffusion as a method to determine teicoplanin susceptibility. There are some limitations in this study though: the small number of teicoplanin-resistant staphylococci in this sample, which requires further studies, and the absence of molecular typing of the samples. Aiming to reduce the possibility of evaluating clonal samples, we observed some demographic and phenotypic features of the isolates in order to include samples that were representative for the whole hospital and showed different patterns of susceptibility to the antimicrobials (Table 1). By considering these observations, our data suggest that the disk-diffusion method can be used to determine teicoplanin susceptibility against staphylococci, at least in this institution. Multicenter studies evaluating a larger number of isolates with established genetic relatedness are highly necessary to extend this conclusion to other institutions. 
Table 1. Distribution of samples according to ward of isolation and antibiotype*.

\begin{tabular}{|c|c|c|c|c|c|}
\hline $\begin{array}{c}\text { Microorganism } \\
\text { (number of } \\
\text { samples) } \\
\end{array}$ & $\begin{array}{l}\text { Origin } \\
\text { (n) }\end{array}$ & $\begin{array}{c}\text { Number of } \\
\text { different } \\
\text { antibiotypes }\end{array}$ & $\begin{array}{c}\begin{array}{c}\text { Microorganism } \\
\text { (number of } \\
\text { samples) }\end{array} \\
\end{array}$ & $\begin{array}{l}\text { Origin } \\
\text { (n) }\end{array}$ & $\begin{array}{c}\text { Number of } \\
\text { different } \\
\text { antibiotypes }\end{array}$ \\
\hline \multirow{10}{*}{$\begin{array}{l}\text { Methicillin } \\
\text { susceptible } \\
\text { S. aureus } \\
\quad \text { (16) }\end{array}$} & $\begin{array}{l}\text { Emergency Room } \\
\text { (5) }\end{array}$ & 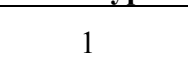 & \multirow{10}{*}{$\begin{array}{l}\text { Methicillin resistant } \\
\text { S. aureus } \\
\text { (15) }\end{array}$} & Dermatology (2) & 1 \\
\hline & Gynecology (1) & 1 & & $\begin{array}{l}\text { Emergency } \\
\text { Room (6) }\end{array}$ & 4 \\
\hline & Heart Surgery (1) & 1 & & $\begin{array}{l}\text { Gastroen- } \\
\text { terology (1) }\end{array}$ & 1 \\
\hline & $\begin{array}{l}\text { Infectious } \\
\text { Diseases (1) }\end{array}$ & 1 & & $\begin{array}{l}\text { Gastro-surgery } \\
\text { (1) }\end{array}$ & 1 \\
\hline & Nephrology (1) & 1 & & $\begin{array}{l}\text { Infectious } \\
\text { Diseases (1) }\end{array}$ & 1 \\
\hline & Neurology (1) & 1 & & $\begin{array}{l}\text { Internal } \\
\text { Medicine (1) }\end{array}$ & 1 \\
\hline & Obstetrics (1) & 1 & & Orthopedic (1) & 1 \\
\hline & Rheumatology (2) & 1 & & $\begin{array}{l}\text { Private } \\
\text { ward (1) }\end{array}$ & 1 \\
\hline & $\begin{array}{l}\text { Transplant Unit } \\
\text { (2) }\end{array}$ & 1 & & $\begin{array}{l}\text { Vascular } \\
\text { Surgery (1) }\end{array}$ & 1 \\
\hline & $\begin{array}{l}\text { Vascular Surgery } \\
\text { (1) }\end{array}$ & 1 & & & \\
\hline \multirow{8}{*}{$\begin{array}{c}\text { Methicillin } \\
\text { susceptible } S \text {. } \\
\text { epidermidis (15) }\end{array}$} & Cardiology (1) & 1 & \multirow{8}{*}{$\begin{array}{l}\text { Methicillin resistant } \\
\text { S. epidermidis } \\
\text { (17) }\end{array}$} & $\begin{array}{l}\text { Emergency } \\
\text { Room (5) }\end{array}$ & 4 \\
\hline & Dialysis (1) & 1 & & $\begin{array}{l}\text { Infectious } \\
\text { Diseases (1) }\end{array}$ & 1 \\
\hline & $\begin{array}{l}\text { Emergency Room } \\
\text { (4) }\end{array}$ & 3 & & Nephrology (1) & 1 \\
\hline & $\begin{array}{l}\text { Emergency Room } \\
\text { ICU(1) }\end{array}$ & 1 & & $\begin{array}{l}\text { Neuro-surgery } \\
\text { (3) }\end{array}$ & 3 \\
\hline & $\begin{array}{l}\text { Infectious } \\
\text { Diseases (2) }\end{array}$ & 2 & & $\begin{array}{l}\text { Newborn ward } \\
\text { (6) }\end{array}$ & 6 \\
\hline & $\begin{array}{l}\text { Internal Medicine } \\
\text { (2) }\end{array}$ & 2 & & $\begin{array}{l}\text { Pediatric ICU } \\
\text { (1) }\end{array}$ & 1 \\
\hline & Nephrology (1) & 1 & & & \\
\hline & Newborn ward (3) & 2 & & & \\
\hline
\end{tabular}

\section{MIC}

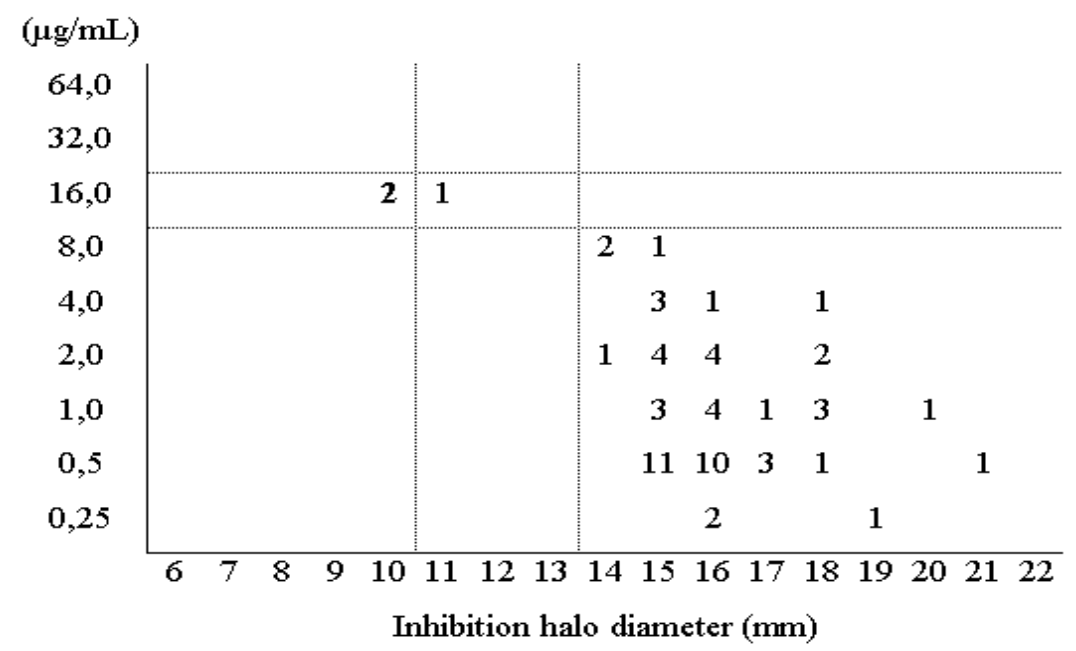

Figure 1. Comparative results between broth microdilution (MIC) and $30 \mu \mathrm{g}$ inhibition zone diameters for teicoplanin tested against 63 clinical staphylococci isolates. Broken lines represent the breakpoint values for teicoplanin (5). Bold numbers represent discordant isolates. 


\section{ACKNOWLEDGEMENTS}

The authors thank the Sanofi-Pasteur Pharmaceutical Company, represented by Mr. Marco Aurélio, for providing teicoplanin for broth microdilution as well as for providing part of the material utilized. The authors also thank the staff of the Microbiological Laboratory from the University Hospital of Botucatu Medical School, São Paulo state, Brazil.

\section{REFERENCES}

1. CDC - Centers for Disease Control and Prevention (2002) Staphylococcus aureus resistant to vancomycin - United States. MMWR Morb. Mortal. Wkly. Rep. 51, 565-567.

2. CDC - Centers for Disease Control and Prevention (2004). Vancomycinresistant Staphylococcus aureus - New York. MMWR Morb. Mortal. Wkly. Rep. 53, 322-323.

3. Cetinkaya, Y.; Falk, P.; Mayhall, C.G. (2000). Vancomycin-resistant enterococci. Clin. Microbiol. Rev. 13 (4); 686-707.

4. CLSI - Clinical Laboratory Standards Institute (2009). Methods for dilution antimicrobial susceptibility test for bacteria that grow aerobically: M07-A8. Clinical Laboratory Standards Institute, Wayne, P.A.

5. CLSI - Clinical Laboratory Standards Institute (2009). Performance standards for antimicrobial susceptibility testing: M100-S19. Clinical Laboratory Standards Institute, Wayne, P.A.

6. CLSI - Clinical Laboratory Standards Institute (2010). Performance standards for antimicrobial susceptibility testing: M100-S20. Clinical Laboratory Standards Institute, Wayne, P.A.

7. Cunha, M. de L.; Sinzato, Y.K.; Silveira, L.V. (2004). Comparison of methods for the identification of coagulase-negative staphylococci. Mem. Inst. Oswaldo Cruz. 99 (8), 855-860.

8. Gemmell, C.G.; Edwards, D.I.; Fraise, A.P.; Gould, F.K.; Ridgway, G.L.; Warren, R.E.; Joint Working Party of the British Society for Joint Working Party of the British Society for Antimicrobial Chemotherapy, Hospital Infection Society and Infection Control Nurses Association (2006). Guidelines for the prophylaxis and treatment of methicillinresistant Staphylococcus aureus (MRSA) infections in the UK. J. Antimicrob. Chemother. 57 (4), 589-608.

9. Keyserling, H.L.; Sinkowitz-Cochran, R.L.; Harris, J.M. 2nd; Levine, G.L.; Siegel, J.D.; Stover, B.H.; Lau, S.A.; Jarvis, W.R.; Pediatric Prevention Network (2003). Vancomycin Use in Hospitalized Pediatric Patients. Pediatrics. 112 (2), e104-e111.

10. Kirst, H.A.; Thompson, D.G.; Nicas, T.I. (1998). Historical yearly usage of vancomycin. Antimicrob. Agents Chemother. 42 (5),1303-1304.

11. NCCLS - National Committee for Clinical Laboratory Standards (1981). Development of in vitro susceptibility testing criteria and quality control parameters: M23-A2. National Committee for Clinical Laboratory Standards, Wayne, P.A.

12. Svetitsky, S.; Leibovici, L.; Paul, M. (2009). The comparative efficacy and safety of vancomycin vs. teicoplanin: Systematic review and metaanalysis. Antimicrob. Agents Chemother. 53 (10), 4069-4079.

13. Trueba, F.; Garrabe, E.; Hadef, R.; Fabre, R.; Cavallo, J.D.; Tsvetkova, K.; Chesneau, O. (2006). High Prevalence of Teicoplanin Resistance among Staphylococcus epidermidis Strains in a 5-Year Retrospective Study. J. Clin. Microbiol. 44 (5), 1922-1923. 